\title{
Effect of stack height and exhaust velocity on pollutant dispersion in the wake of a building
}

\author{
M. Lateb ${ }^{\mathrm{a}, *}$, C. Masson ${ }^{\mathrm{a}}$, T. Stathopoulos ${ }^{\mathrm{b}}$, C. Bédard ${ }^{\mathrm{a}}$ \\ ${ }^{a}$ Department of Mechanical Engineering, ÉTS (École de technologie supérieure) \\ 1100 Notre-Dame West, Montreal, H3C 1 K3 Canada \\ ${ }^{b}$ Department of Building, Civil and Environmental Engineering, Concordia University \\ 1455 de Maisonneuve Blvd. West, Montreal, H3G 1 M8 Canada
}

\begin{abstract}
The dispersion of pollutants exhausted from a building roof stack located in the wake of a tower is investigated by means of the realizable $k-\epsilon$ turbulence model. Variations in stack height and pollutant exhaust velocity are considered to assess their influence on the distribution of pollutant concentrations in the neighbourhood of the emitting building. In order to determine optimum locations for freshair intakes, the worst case is considered, namely when the wind originates directly upstream of the tower and places the emitting building in its wake. Special attention is given to the evolution of the plume and distribution of pollutant concentrations on the roof and windward wall of the emitting building, as well as on the leeward wall of the upwind tower. Simulation results are compared to wind tunnel experiments conducted in a boundary layer wind tunnel. For this particular configuration, the paper shows that increasing the stack height has an effect similar to that obtained by increasing the momentum ratio, but with some differences, depending upon which wall of the two buildings is considered. On the emitting building, the leeward wall has the lowest concentration values for all stack heights and momentum ratios considered; thus this is the best location for fresh-air intakes. However, for the tower, fresh-air intakes should not be located on the leeward wall due to high pollutant concentrations. The results show completely different pollutant dispersion patterns from those for an isolated building. This highlights the importance of accounting for structures that lie in close proximity to the emitting building.
\end{abstract}

Keywords: Computational fluid dynamics (CFD), Atmospheric boundary layer (ABL), Pollutant dispersion, Pollutant exhaust velocity, Stack height, Turbulence model

\section{Introduction}

Nowadays, pollutant dispersion from roof stacks in urban areas is a factor that can seriously affect the quality of fresh air at intakes of the surrounding buildings, potentially compromising the wellbeing of these buildings' occupants. Finding a way to eliminate this harmful and sometimes hazardous problem poses a challenge for the scientific and engineering community.

Many parameters affect the dispersion of pollutants from roof stacks, including wind speed and direction; stack exhaust velocity; the presence of surrounding buildings; topography; stack location and height; atmospheric stability, and initial pollutant concentration (White and Stein, 1990). Some of these parameters (e.g. stack location and height, fresh-air-intake locations, and pollutant exhaust

*Corresponding author. Tel.: +1 5143968800 ext. 7838; fax: +1 5143968530

Department of Mechanical Engineering, ÉTS (École de technologie supérieure)

1100 Notre-Dame West, Montreal, H3C 1K3 Canada

Email address: mohamed.lateb@etsmtl.ca (M. Lateb) 
velocity) are easier to study than others in terms of respecting the air quality norms inside the surrounding and emitter buildings. Stack height and pollutant exhaust velocity are the parameters of interest for this study.

Pollutant dispersion studies are generally carried out using field measurements, wind tunnel testing and, more recently, by numerical simulation with Computational Fluid Dynamics (CFD). Those carried out at field and wind tunnel scales, as reviewed by Blocken and Stathopoulos (2008), provide concentration discrete-point data. CFD allows for easier control of each parameter and can be a powerful tool for parametric analysis of the factors influencing flow and dispersion processes. In this numerical study, the objective is to determine how stack height and pollutant exhaust velocity influence the emitted pollutant plume and dispersion, in order to find the fresh-air-intake locations which best respect air quality norms. The results are compared with experimental measurements carried out by Stathopoulos et al. (2004) in the boundary layer wind tunnel of Concordia University.

\section{Review of previous dispersion studies}

Several studies have been carried out previously to evaluate pollutant dispersion around buildings. Because incoming flow is complex and highly turbulent, most studies have been conducted on isolated buildings (sometimes on cubic buildings) in order to simplify not only the flow field (e.g. Meroney et al., 1999; Blocken et al., 2008; Tominaga and Stathopoulos, 2009; Santos et al., 2009; Tominaga and Stathopoulos, 2010) but also the implications of certain parameters. As such, the features of the wind pattern around an isolated building are now well established in the wind engineering community, as mentioned by several authors (e.g. Meinders and Hanjalic, 1999; Blocken and Stathopoulos, 2008; ASHRAE, 2009; Blocken et al., 2011). As stated by Blocken et al. (2011) these studies serve as generic basic situations and have proven quite suitable for validation, verification and sensitivity analyses. Although other studies have been conducted in complex sites (e.g. building groups, urban sites, building complexes), starting from the 1990s, fundamental studies focusing to multiple-building configurations have been increasingly performed. In these cases, the parameters generally studied are wind direction (e.g. Yassin et al., 2005; Gousseau et al., 2011); wind speed (e.g. Stathopoulos, 2006); the influence of surrounding buildings on flow and diffusion fields (e.g. Murakami et al., 1991; Chavez et al., 2011), or one or more of the other parameters mentioned in the previous section.

Turbulent plumes exhausted from a building stack have been studied and compared with experimental data gathered by Onbasioglu (2001). These studies show that higher exhaust velocities affect the entrainment mechanism and that decreasing jet velocity not only limits the vertical rise of a buoyant plume, but also restricts dilution as compared to higher jet velocities. Although exit temperature does not affect the lateral and vertical coordinates of plume formation, it decreases the plume in size and its concentration also decreases more rapidly towards the inside of the stack.

Nakiboglu et al. (2009) have recently studied pollutant dispersion from a stack located in an atmospheric boundary layer. Concentration and velocity fields in a vertical plane were compared with wind tunnel measurements. The experimental concentration field was determined via two methods: Aspiration Probe (AP) measurements and Light Scattering Technique (LST). Large Scale-Particle Image Velocimetry (LS-PIV) was used to obtain the velocity field. Although good agreement was found between CFD and AP measurements when using a Schmidt number of 0.4, a correction function had to be applied for LST measurements in order to obtain close agreement.

An analysis of the Reynolds number effect on plume trajectories for pollutants emitted by a stack was carried out in wind tunnel experiments by Contini et al. (2009); the critical Reynolds number of stack emissions $(\mathrm{Re})_{s}$ proved to be approximately 3000 for the particular case studied. The effect of having a lower $(\mathrm{Re})_{s}$ than the indicated threshold led to an overestimation of the plume rise in wind tunnel measurements as compared to full-scale emission. This observation was due to the corresponding $(\mathrm{Re})_{s}$ value in full scale, which is much higher, leading to the distortion of the emission velocity profile caused by an excess in the emitted momentum flux.

A wind tunnel study evaluating the influence of stack height was carried out by White and Stein (1990). Their aim was to determine the minimum stack height necessary in order to keep the stack 
outlet free of upstream wake effects. Several cases using various stack heights, stack locations and wind directions were studied. Within the same context, in order to determine laboratory exhaust stack height in order to avoid re-entry of exhaust and possible air quality problems, Ratcliff and Sandru (1999) used the dilution prediction equations from the ASHRAE (1997) handbook as well as the Halitsky dilution criterion to provide a method for specifying stack heights in future handbooks. The authors suggested using a comparison with wind tunnel data for the revised equations.

In previous cases, Blocken et al. (2008), Lateb et al. (2010a) and Gousseau et al. (2011) have conducted their studies on the same site with the present study. All these works have a common point: to compare numerical simulation results with experimental results obtained at Concordia University wind tunnel. Gousseau et al. (2011) have reproduced the whole site configuration of the wind tunnel experiment using two different turbulence models, i.e., RANS (Reynolds-Averaged Navier-Stokes) standard $k-\epsilon$ and LES (Large Eddy Simulation), and have validated their work for two different wind directions by comparison with wind tunnel measurements. Blocken et al. (2008) have simplified the computational grid including only the BE building, and the simulations were performed with the Reynolds Stress Model (RSM) and with enhanced wall treatment. Lateb et al. (2010a) have considered a two-building configuration for two different scales, i.e., full scale (1:1) and wind tunnel scale (1:200), using two stack heights and two exhaust pollutant velocities for each scale.

\section{Problem description}

As introduced in the previous section, this study refers to the same site, and uses the same mathematical and numerical models as those used in Lateb et al. (2010a). In the following sections, general information is given concerning the computational domain and governing equations.

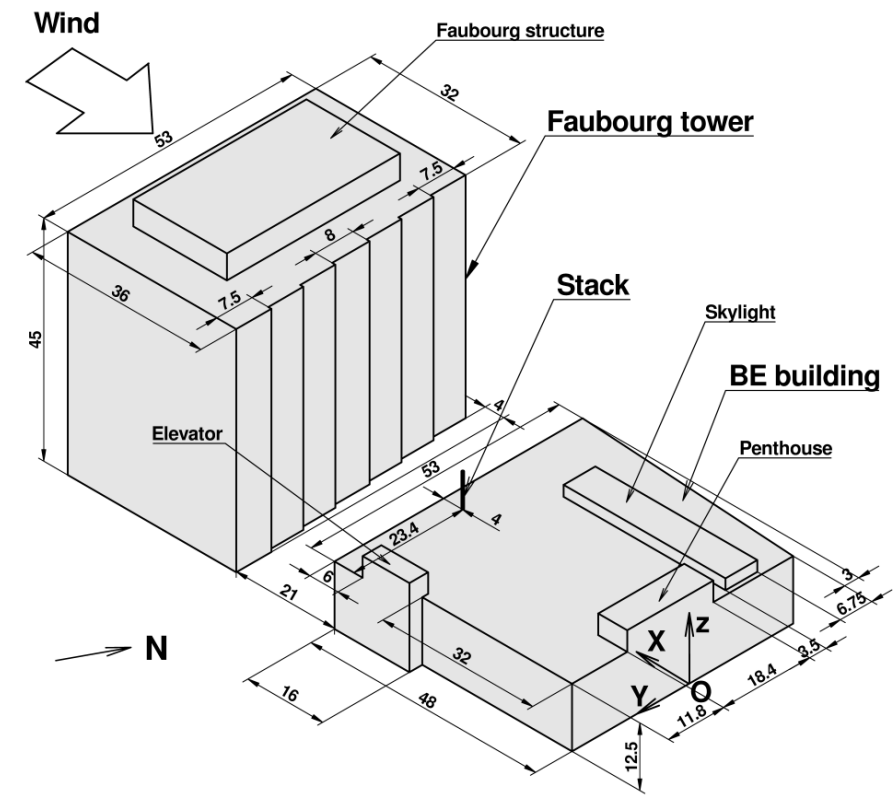

Figure 1: General view of the two buildings, their structures and their full-scale dimensions. All dimensions in [m].

\subsection{Geometric model}

The geometry considered in this study is comprised of two inline buildings (referred to as the BE building and the Faubourg tower), both located in an urban zone in downtown Montreal. Fig. 1 shows the site configuration alone with the dimensions of the two structures. The wind arrives perpendicular to the Faubourg tower from the southwest and places the BE building in its wake. For the BE building, 
only the three most prominent rooftop structures have been taken into account; an entry located on the windward wall and a one-metre-high parapet running along the roof perimeter have been omitted. It is worth noting that the leeward wall of the Faubourg tower takes the form of a horizontal staircase. Consequently, the spacing between the two buildings increases by 4 metres from the southeast to the northwest ends.

\subsection{Computational domain}

Calculations were carried out on a hexahedral grid in all parts of the domain composed of $187 \times$ $126 \times 102$ cells. The grid was fairly coarse near the boundaries of the domain, with cells concentrated near the stack and the building walls, as can be seen in Figs. 2 and 3. The top of the domain is located $5 H_{F b}$ from the top of the Faubourg tower and the lateral boundaries are $4.5 H_{F b}$ distant from each building. A symmetry condition is imposed for all (i.e., top and lateral) sides of the domain. This condition implies that there is zero normal velocity and zero normal gradients for all variables on these planes. The domain entry is at a distance of $6.5 \mathrm{H}_{F b}$ upstream of the Faubourg tower, and a velocity inlet is imposed as boundary condition. The profiles of velocity and turbulence properties, i.e., turbulent kinetic energy $k$ and turbulent rate dissipation $\epsilon$, are specified and listed in Table 1. The error related to horizontal inhomogeneity is evaluated by performing a simulation in an empty computational domain using a specified wall shear stress, at the bottom of the grid, as suggested by Blocken et al. (2007) and the results obtained are comparable to that work. The domain exit located at $11 H_{F b}$ downstream of the BE building has an outflow boundary condition. This means that the flow is assumed to be fully developed and there is no diffusion flux for any of the flow variables. An error analysis of the grid refinement was performed on three computational grids, i.e., 1.59, 1.99 and 2.29 million cells, following the recommendations of Celik et al. (2008). As the average relative error of concentrations $K$ obtained for two successive refined grids was found to be less than $2 \%$, the grid of 2.29 million cells was used for the remainder of the study. Note that the grid configuration shown in in Fig. 3 was created using the software Gambit 2.4.6 with a skewness angle less than 0.42 for all hexahedral cells. For near-wall modelling, the enhanced wall function is used; the grid distribution has been controlled by clustering the mesh towards the walls in such a way that this near-wall treatment can be applied. The obtained $\mathrm{Y}^{+}$values for near-wall cells are in the range of 2 to 5 . A no-slip condition is used at all walls of the buildings with zero heat flux.

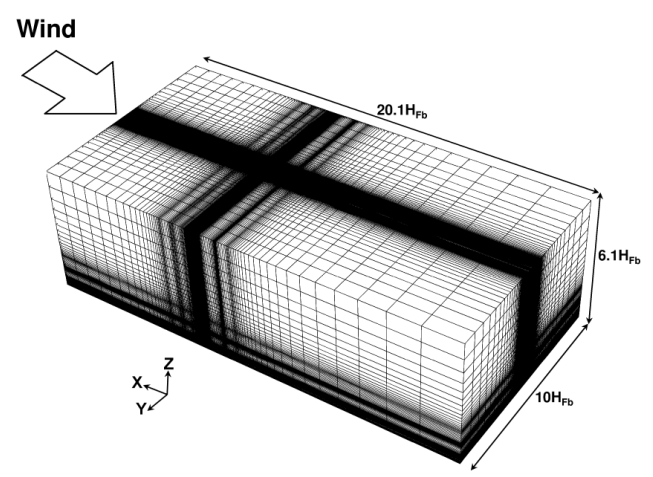

Figure 2: Dimensions of the grid.

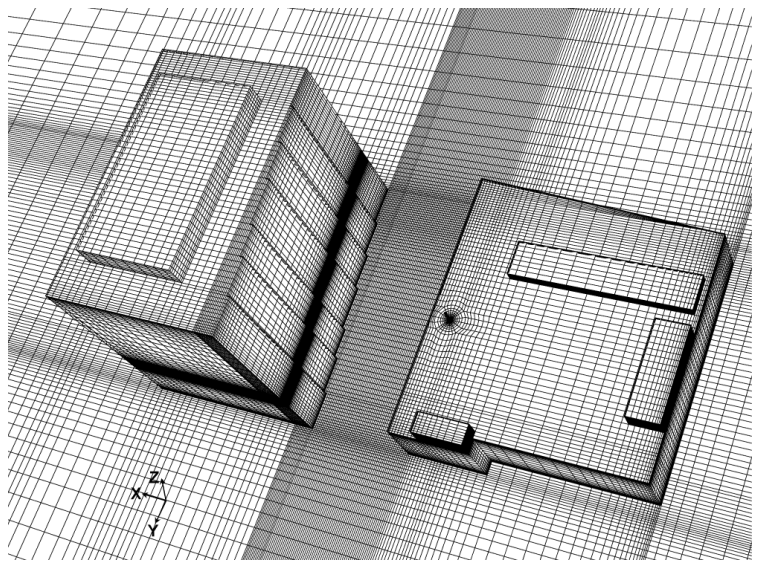

Figure 3: General view of the two buildings.

The wind within the simulated domain can be regarded as an incompressible, turbulent, inert flow. Air and pollutant densities are assumed to be constant and equal. According to Sini et al. (1996), this assumption holds for most environmental applications in the lower atmosphere. Stack discharge was considered to be a neutrally buoyant, passive gas without thermal effects. Table 1 shows a summary 
of the test cases for various stack heights. The first case, i.e., the case using $h_{s}=1 \mathrm{~m}$ and $M=2.2$, was reproduced without the Faubourg tower upstream of the BE building. The parameters $h_{s}$ and $M$ represent stack height and momentum ratio, respectively, and $T I_{s}$ is the pollutant turbulence intensity at stack's exit.

\begin{tabular}{|c|c|c|c|c|c|c|c|}
\hline \multirow{2}{*}{$\begin{array}{c}\text { Stack } \\
\text { height } \\
200 h_{s}[\mathrm{~m}]\end{array}$} & \multirow{2}{*}{$\begin{array}{l}\text { Momentum } \\
\text { ratio } \\
M=w_{e} / U_{H}\end{array}$} & \multirow{2}{*}{$\begin{array}{c}\text { Exhaust } \\
\text { velocity } \\
w_{e}\left[\mathrm{~m} \mathrm{~s}^{-1}\right]\end{array}$} & \multirow{2}{*}{$\begin{array}{c}\text { Turbulent } \\
\text { intensity } \\
T I_{s}[\%]\end{array}$} & \multicolumn{4}{|c|}{ Profiles at the entry of the domain } \\
\hline & & & & $\begin{array}{c}\text { Profile } \\
U(z)\end{array}$ & $\begin{array}{c}\text { Profile } \\
k(z)\end{array}$ & $\begin{array}{c}\text { Profile } \\
\epsilon(z) \\
\end{array}$ & $\begin{array}{c}\text { Profile } \\
T I(z)\end{array}$ \\
\hline \multirow{2}{*}{1} & 2.2 & 13.88 & 6.2 & \multirow{9}{*}{$14.5 \times z^{0.3}$} & \multirow{9}{*}{$1.25 / z^{0.4}$} & \multirow{9}{*}{$2.17 / z$} & \multirow{9}{*}{$0.063 / z^{0.5}$} \\
\hline & 5 & 31.55 & 5.6 & & & & \\
\hline \multirow{3}{*}{3} & 2.2 & 13.88 & 6.2 & & & & \\
\hline & 4.5 & 28.40 & 5.7 & & & & \\
\hline & 5 & 31.55 & 5.6 & & & & \\
\hline \multirow{2}{*}{4} & 2.2 & 13.88 & 6.2 & & & & \\
\hline & 5 & 31.55 & 5.6 & & & & \\
\hline \multirow{2}{*}{7.2} & 2.2 & 13.88 & 6.2 & & & & \\
\hline & 5 & 31.55 & 5.6 & & & & \\
\hline
\end{tabular}

Table 1: Summary of simulation test cases.

\subsection{Governing equations and turbulence model}

The equations governing the flow field consist of the continuity and Reynolds-Averaged NavierStokes equations which are an adequate representation of the wind tunnel's reality for a comparison with a wind tunnel experiments according to Franke et al. (2007). The realizable $k-\epsilon$ turbulence model was used, following the work of Wang (2006), to close the system, which requires the solution of two supplementary transport equations: one for $k$ (turbulence kinetic energy) and another for $\epsilon$ (turbulence dissipation rate). The dispersion equation is given by the convection-diffusion equation for species transport. Full-model details are available in Lateb et al. (2010a).

Since the wind tunnel concentration measurements are provided in non-dimensional form, all calculated concentrations were normalized by

$$
K=\frac{4 C U_{H} H_{B E}^{2} 10^{-6}}{\pi d_{s}^{2} w_{e}}
$$

where $C$ is the pollutant concentration [ppb], $U_{H}$ is the wind velocity at the roof height of the BE building $\left[\mathrm{m} \mathrm{s}^{-1}\right] ; H_{B E}$ is the BE building height $[\mathrm{m}] ; d_{s}$ is the stack diameter $[\mathrm{m}]$, and $w_{e}$ is the pollutant exhaust velocity from the stack $\left[\mathrm{m} \mathrm{s}^{-1}\right]$. Note that the pollutant source concentration, $C_{e}$, is equal to 1.

\section{Model validation}

The experimental data used to validate the numerical simulations were obtained from a detailed wind tunnel study by Stathopoulos et al. (2004). The surroundings were modelled up to points as far as $250 \mathrm{~m}$ upwind; buildings within $50 \mathrm{~m}$ were included in the downwind direction. In this paper, the study is limited to the two buildings concerned, i.e., the BE building and the Faubourg tower, as shown previously in Fig. 1. As explained by Blocken and Stathopoulos (2008), the wind tunnel experiment provides concentrations from samplers located at different locations on the BE roof and leeward wall of the Faubourg tower. The sampler locations in the wind tunnel experiment are shown in Figs. 4 and 5. Most of the measured concentrations were obtained for stack heights of $1 \mathrm{~m}$ and $3 \mathrm{~m}$. The only measurements obtained for higher $h_{s}$ are those collected at samplers $\mathrm{R}_{4}, \mathrm{R}_{17}$ and $\mathrm{P}_{2}$ located along the stack axis on the $\mathrm{BE}$ roof and at samplers $\mathrm{F}_{B 1}, \mathrm{~F}_{B 2}$ and $\mathrm{F}_{B 3}$ on the Faubourg leeward wall, using a momentum ratio, $M$, equal to 2.2. The following figures provide a detailed comparison between the wind tunnel experiments and simulation results. 

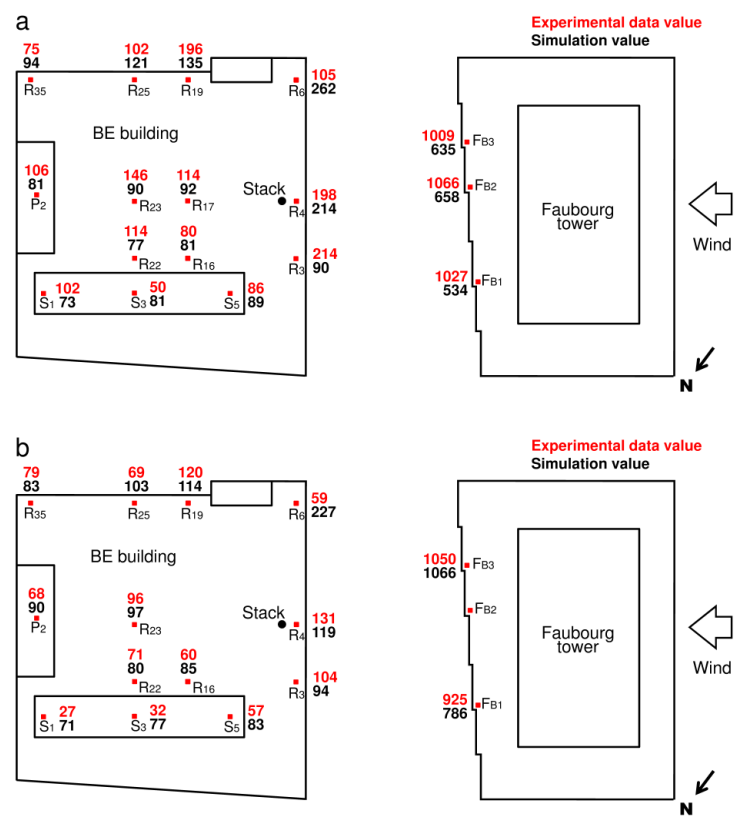

Figure 4: Simulation and wind tunnel values for $K$ for stack height $h_{s}$ of $1 \mathrm{~m}$. For (a) $M=2.2$ and (b) $M=5$.
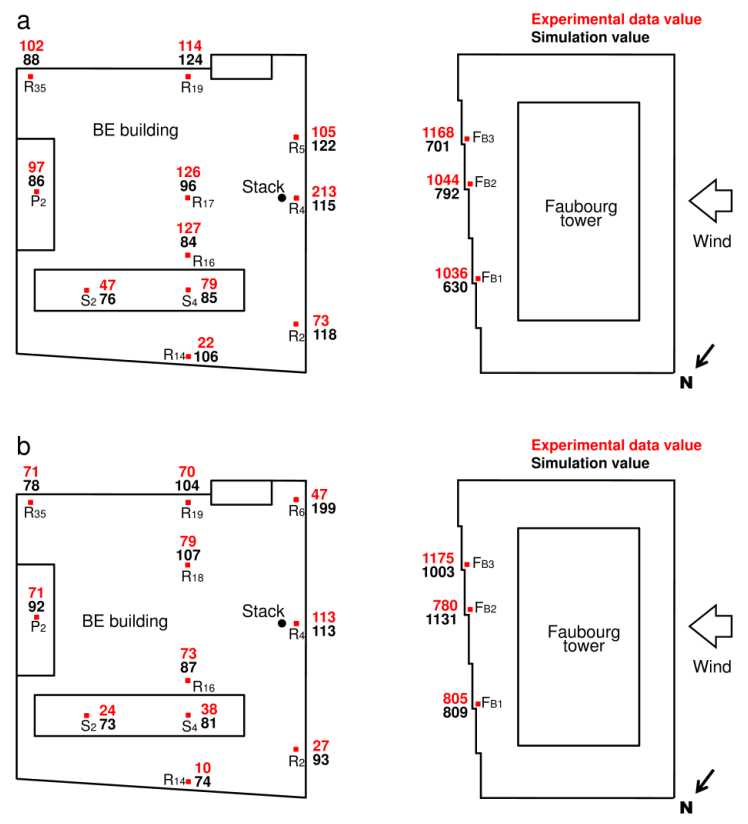

Figure 5: Simulation and wind tunnel values for $K$ for stack height $h_{s}$ of $3 \mathrm{~m}$. For (a) $M=2.2$ and (b) $M=4.5$.

Figs. $4 \mathrm{a}$ and $4 \mathrm{~b}$ show the non-dimensional concentrations at samplers on the BE building roof and on the Faubourg tower's leeward wall for a stack height of $1 \mathrm{~m}$, at two different momentum ratios of 2.2 and 5, respectively. At the majority of the samplers, the experimental concentrations are underestimated for the smaller momentum ratio. $K$ is overestimated only upwind of the BE building 
$\left(\mathrm{R}_{4}\right.$ and $\left.\mathrm{R}_{6}\right)$ and in the southeast corner. For the higher momentum ratio $(M=5)$, the opposite tendency is noted, and $K$ is underestimated at only a few of the samplers; this tendency is also shown upwind of the $\mathrm{BE}$ building. On the leeward wall of the Faubourg tower, $K$ is underestimated at all samplers by around $40 \%$. By increasing the pollutant velocity, the differences become less pronounced (about $15 \%$ ) at sampler $\mathrm{F}_{B 1}$. An overestimation of under $2 \%$ is noticed at sampler $\mathrm{F}_{B 3}$, however.

For a stack height of $3 \mathrm{~m}$, as indicated in Fig. 5, the results for the lower momentum ratio show an underprediction at samplers located on the BE roof centre region and the Faubourg tower leeward wall. Increasing the pollutant exhaust velocity produces an overestimation of $K$ for the majority of samplers, except at sampler $\mathrm{F}_{B 3}$, where the underestimation persists. The differences between samplers $\mathrm{F}_{B 1}$ and $\mathrm{F}_{B 3}$ are probably due to the staircase form of the Faubourg leeward wall, which does not permit flow field symmetry between the buildings. At sampler $\mathrm{R}_{4}$ near the stack and for both stack heights, a reduction in the difference between the wind tunnel and simulated values is noted with increasing pollutant velocity; for instance, the difference is smaller for the lower than for the higher stack height. However, $K$ values at $\mathrm{R}_{4}$ are identical for the higher momentum ratio, with $h_{s}=3 \mathrm{~m}$.

Fig. 6 shows the scatter plots of the non-dimensional concentration $K$ values for wind tunnel tests and CFD simulations for stack heights of 1 and 3 metres. The corresponding correlation coefficients, $\mathrm{R}$, are 0.93 and 0.92 , respectively. About $80 \%$ of the concentration values are positioned within a range of factor 2 , as indicated by points situated between the dashed lines on each side of the median line. The averaged errors, $e_{a}$, for calculated and experimental values, are about $45 \%$ and $88 \%$ for stack heights of $1 \mathrm{~m}$ and $3 \mathrm{~m}$, respectively.
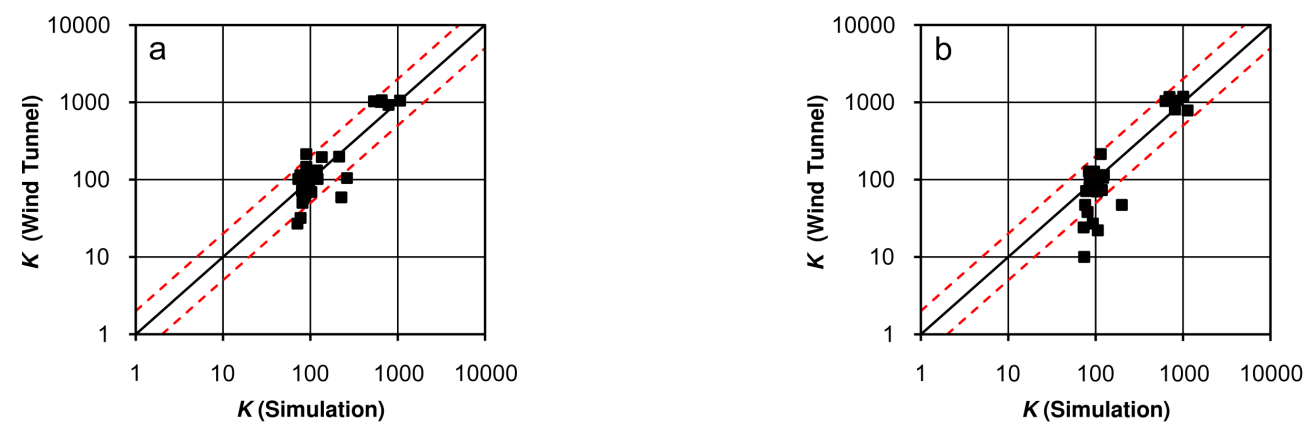

Figure 6: Scatter plots of simulation and wind tunnel $K$ data for stack heights of (a) $h_{s}=1 \mathrm{~m}$ and (b) $h_{s}=3 \mathrm{~m}$.

Fig. 7 shows the distribution of $K$ at samplers $\mathrm{R}_{4}, \mathrm{R}_{17}$ and $\mathrm{P}_{2}$ with increasing stack height for a momentum ratio of 2.2. For wind tunnel scale simulations, a small increase in $K$ at all samplers is observed with increasing stack height. Only at sampler $\mathrm{R}_{4}$ is there a clear decrease in $K$ between 1 and 3 metres of stack height. For stack heights between 3 and 5 metres, however, this phenomenon is observed at all three samplers in the wind tunnel experiments. This may be explained by the fact that the pollutant plume reaches levels above the roof, where recirculation is present. The strong dilution recorded, which halves the concentration value, is observed at lower heights in the simulation results than in the wind tunnel experiments. The recirculating flow in the tower's wake, particularly above the central roof portion of the BE building, seems to be situated at a lower level in the numerical simulations than in the wind tunnel experiments. Beyond this critical stack height (between 1 and 3 metres), concentrations still increase in the numerical simulations at all samplers, while they are observed to decrease slightly in wind tunnel experiments. However, the concentrations are still overestimated at samplers $\mathrm{R}_{17}$ and $\mathrm{P}_{2}$ which are located far away downstream from the stack. At sampler $\mathrm{R}_{4}$ near the stack, results are comparable. These overestimations are expected, since the pollutant plume is continually being drawn by the recirculating flow to a lower level than in the wind tunnel experiments. 

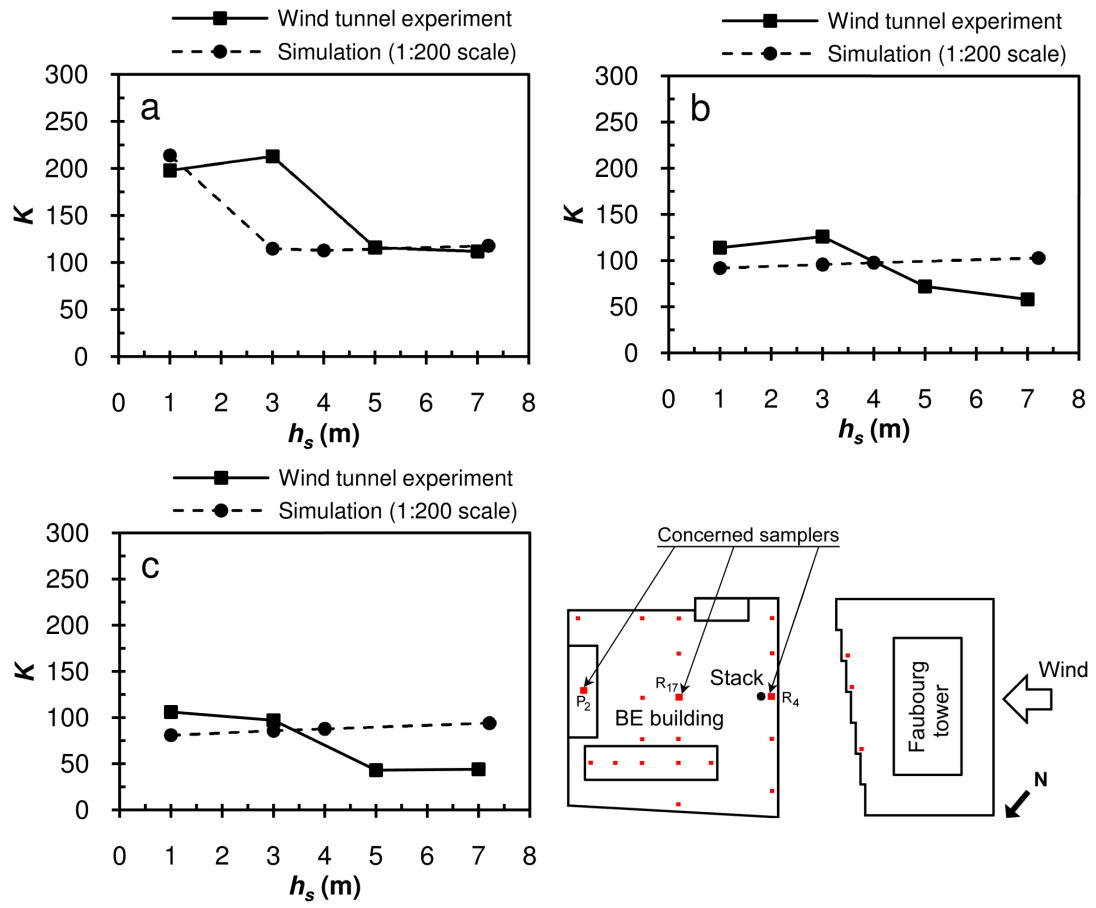

Figure 7: Measured and calculated concentrations $K$ for $M=2.2$ and various stack heights $h_{s}$, on the BE building's roof at samplers (a) $R_{4}$, (b) $R_{17}$ and (c) $P_{2}$.

For the samplers located at higher levels on the tower's leeward wall, i.e., $\mathrm{F}_{B 1}, \mathrm{~F}_{B 2}$ and $\mathrm{F}_{B 3}$, as shown in Fig. 8, the same abrupt decrease in concentration levels is observed between 3 - and 5-metre stack heights in wind tunnel results. Conversely, the numerical model predicts a slight increase. The higher altitude of the recirculation zones above the BE roof in the wind tunnel, as compared to the simulation experiments, remains the best explanation for these observations. The plume exhausted from the stack is transported higher in the wind tunnel than in the simulation, even for the lowest stacks, as can be seen through the values obtained for stacks of 1 and 3 metres. In the case of the higher stacks, the wind tunnel concentrations increase for the southeast direction from the sampler $\mathrm{F}_{B 1}$ to $\mathrm{F}_{B 3}$. This is expected, since the wider opening at the lateral northwest side between the two buildings favours a strong stream dilution from that point, as compared to the opposite side. The concentration values in the simulation results remain comparable, in the case of higher stacks, between $\mathrm{F}_{B 2}$ and $\mathrm{F}_{B 3}$. It is possible that even the lateral recirculation zones are poorly reproduced in the upper section, as previously found - see Lateb et al. (2010a).

The discrepancies found between CFD simulations and experimental results can be associated to limitations in the wind tunnel experiments or the numerical simulations. Since experimental tests were carried out respecting all the necessary criteria, as stated by Stathopoulos et al. (2004), and according to statements made by several authors (e.g. Blocken et al., 2008; Tominaga and Stathopoulos, 2009, 2010; Lateb et al., 2010b) concerning the capabilities of steady state RANS for unsteady flows, the most probable source of discrepancies seems to be related to the weakness of the steady state RANS approach. The differences observed in Fig. 8 suggest that steady state results in separated flow may be biased to high and/or low concentrations.

As mentioned by Blocken and Stathopoulos (2008), the flow pattern exhibits a strong degree of unsteadiness, while the separation and re-attachment points determined by the interaction of aerodynamic forces fluctuate with perturbations of the overall flow field. Since the wake is characterized by strong vortices shed from the tower's leeward sides and roof, the steady state nature of a RANS approach remains the main suspected cause for poor resolution of the wake zone. Notwithstanding the 
above, the steady state model used in the present study provides comparable results with the wind tunnel experiments as can be seen through the scatter plots shown in Fig. 6.
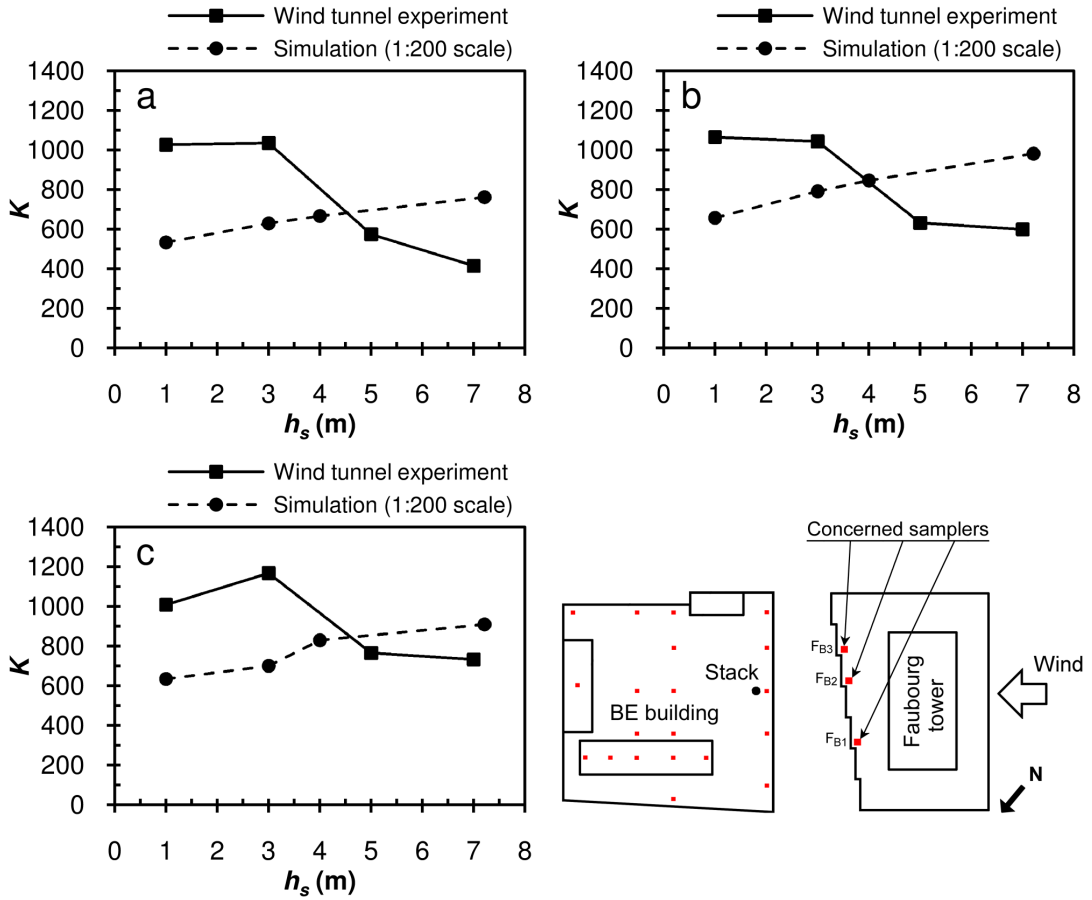

Figure 8: Measured and calculated concentrations $K$ for $M=2.2$ and various stack heights $h_{s}$, on the Faubourg tower's leeward wall at samplers (a) $\mathrm{F}_{B 1}$, (b) $\mathrm{F}_{B 2}$ and (c) $\mathrm{F}_{B 3}$.

\section{Results and discussion}

In this section, results are presented mainly in the form of non-dimensional iso-concentration contours obtained using numerical simulations for various cases studied on the roof and windward wall of the BE building, as well as on the Faubourg tower's leeward wall. Concentrations on the BE building's lateral walls are also assessed to obtain the best air intake locations for the BE building, in order to prevent exhausted pollutant from recycling. One case with a stack height of $1 \mathrm{~m}$ and a momentum ratio of 2.2 was studied without taking the tower upstream of the BE building into account; this was done to draw attention to the need to consider obstacles and buildings in the vicinity of the building of interest.

\subsection{Concentrations on the BE building's roof for various stack heights}

Fig. 9 shows the non-dimensional iso-concentration contours on the BE building roof for various stack heights obtained using a momentum ratio of 2.2. Since the stack is located in the upstream part of the roof, the emitted plume is entirely swept along the upstream direction by the recirculation flow, particularly in the case of the lowest stack. Clearly, the most critical concentrations are observed for lower stack heights in that area of the roof. The concentrations become less significant further from the upstream edge: low concentrations are recorded further away, downstream of the roof. The iso-concentration contours are oblique with respect to the upstream edge, with a decrease in their values from the upstream edge towards the downstream area of the roof. 

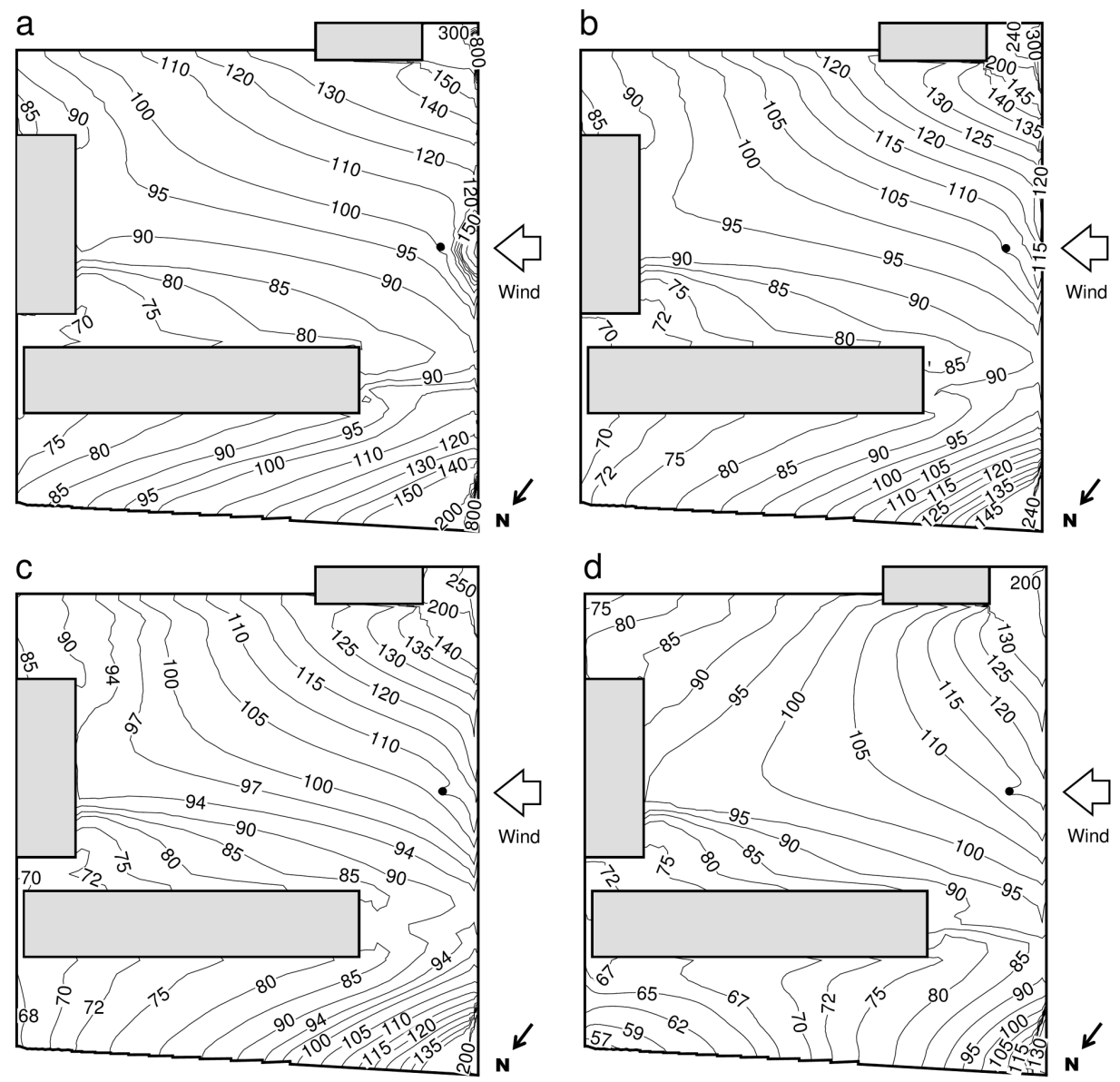

Figure 9: Simulation iso-concentration contours obtained on the roof of the BE building for various stack heights $(M=2.2)$, (a) $h_{s}=1 \mathrm{~m}$, (b) $h_{s}=3 \mathrm{~m}$, (c) $h_{s}=4 \mathrm{~m}$ and (d) $h_{s}=7.2 \mathrm{~m}$.

Concentrations are higher along the upstream edge of the roof, with the strongest concentrations grouped at the extremities of that edge and in the direction upstream of the stack. On the roof, the iso-concentration contours appear arc-like, with peaks located in the upwind part of the penthouse structure. For $h_{s}=1 \mathrm{~m}$ and just upstream of the stack, the iso-concentration contours form halfcircles, whose centres are located towards the upstream edge of the roof. The effect of stack height on the distribution of the iso-contours is such that the strongly concentrated pollutant zones, at the extremities of the upstream edge, gradually become diluted as stack height increases. The downstream regions of the roof remain at concentration levels that are comparable to levels observed at lower heights. For taller stacks, such as $h_{s}=7.2 \mathrm{~m}$, the iso-concentration contours of the southeast part of the roof become curved in such a way as to form arcs with peaks directed towards the northeast, as shown in Fig. 9d.

Lastly, increasing the stack height significantly does not greatly change the concentration levels obtained over the roof, except in the upstream area. Indeed, the BE building's roof is located entirely inside the wake region of the Faubourg tower, and $K$ is smeared out uniformly on the roof, except at the upstream lateral sides, which are characterized by their particular forms (i.e., tilted and set back). The wind flow circumventing the tower modifies the distribution of $K$ imposed by the wake of the upstream tower.

Fig. 10 shows the evolution of the iso-concentration contours for various stack heights when the momentum ratio is greater $(M=5)$. In these cases, the iso-concentration contours with half-circle 
form observed previously at the front of the stack on Fig. 9a do not exist, even for the lowest stack. The previous changes in the iso-concentration contour pattern observed on the southeast part of the roof for $h_{s}=7.2 \mathrm{~m}$ with $M=2.2$, had already appeared for a stack height of 3 metres, as can be seen on Fig. 10b. Increasing the exhaust velocity has the same impact as does increasing stack height on the $\mathrm{BE}$ roof. Indeed, this is clearly illustrated when the iso-concentration contour configurations of Figs. $9 \mathrm{~d}$ and $10 \mathrm{~b}$ are compared. These two figures correspond to the case where a stack height and an exhaust velocity increased by factors of 2.4 and 2.3 , respectively, where $h_{s}=3 \mathrm{~m}$ and $M=2.2$, as shown in Fig. 9b.
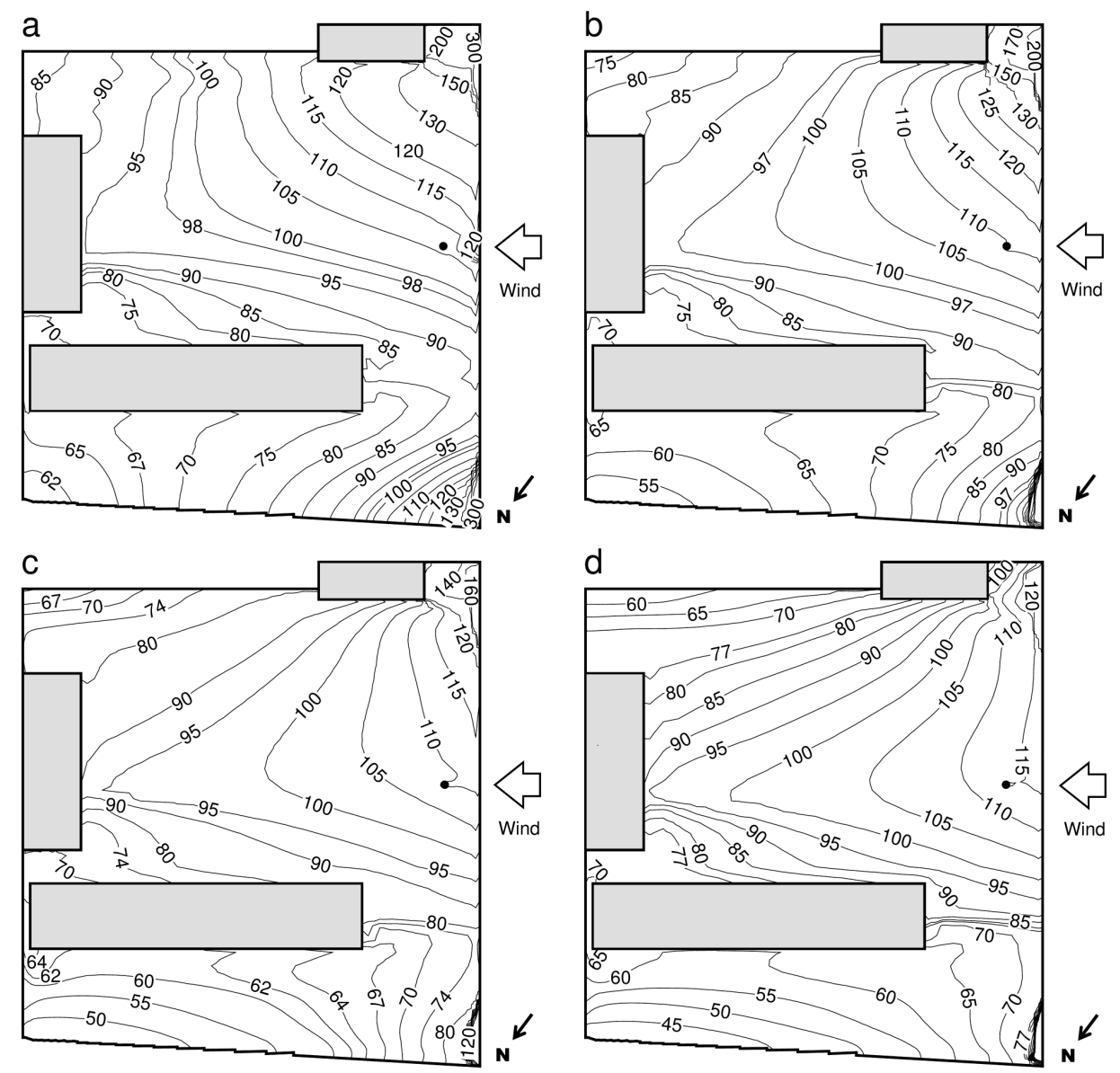

Figure 10: Simulation iso-concentration contours obtained on the roof of the BE building for various stack heights $(M=5)$, (a) $h_{s}=1 \mathrm{~m}$, (b) $h_{s}=3 \mathrm{~m}$, (c) $h_{s}=4 \mathrm{~m}$ and (d) $h_{s}=7.2 \mathrm{~m}$.

\subsection{Concentrations on the BE building's windward wall for various stack heights}

As indicated in Fig. 11, the values for iso-concentration contours obtained on the windward wall of the BE building are higher than those observed on the BE roof. Most of the emitted pollutant is transported by the recirculation flow towards the region between the two buildings. This explains the strong concentrations displayed over the BE building's windward wall. The iso-contours on this facade are arc-shaped and their peaks are flattened at the top level of the wall. The highest iso-concentration contours are clustered near the ground because the pollutant directed to this area is imprisoned by the vortices occurring there. The increase in stack height produces a displacement of these concentrated iso-contours towards the southeast direction, as shown in Figs. 11a to 11d. 

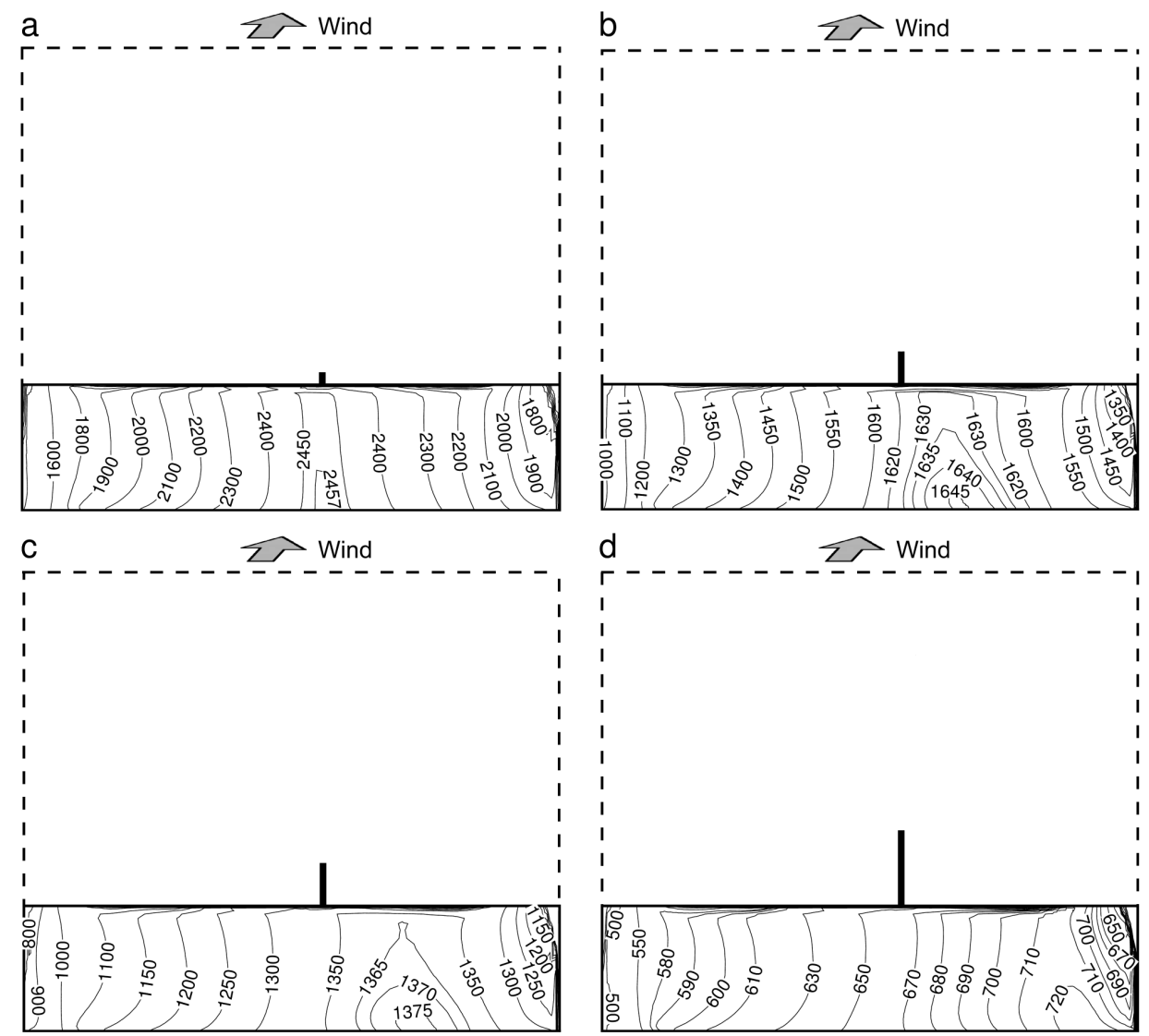

Figure 11: Simulation iso-concentration contours obtained on the windward wall of the BE building for various stack heights $(M=2.2)$, (a) $h_{s}=1 \mathrm{~m}$, (b) $h_{s}=3 \mathrm{~m}$, (c) $h_{s}=4 \mathrm{~m}$ and (d) $h_{s}=7.2 \mathrm{~m}$.

For a low stack $\left(h_{s}=1 \mathrm{~m}\right)$ with a low momentum ratio $(M=2.2)$ as indicated in Fig. 11a, the higher iso-concentration contours are found below the stack. For the highest stack with the same momentum ratio, these contours move to the southeast part of the wall (the right side in this figure) as shown in Fig. 11d. For the larger momentum ratio $(M=5)$ shown in Fig. 12, the higher isoconcentration contours have already reached the southeast extremity of the wall with the low stack height $\left(h_{s}=1 \mathrm{~m}\right)$, as shown in Fig. 12a. These contours remain at the same location even for a taller stack $\left(h_{s}=7.2 \mathrm{~m}\right)$ as can be seen in Fig. 12d. It appears that the pollutant is trapped in that lower area between the two buildings. The lateral recirculation flow induced by the wind circumventing the upstream tower by the southeast side prevents the higher iso-concentration contour displacement from leaving the area between the two buildings.

The pollutant displacement observed on the windward wall of the BE building at $M=2.2$ is probably due to the lack of symmetrical shape in the region between the two buildings caused by the "staircase" form of the tower's leeward wall (see Fig. 4). Indeed, the particular form of the leeward wall offers favourable access for the lateral wind flow from the northwest side because of its wider opening as compared to the southeast side. The lower region between the two buildings is continuously fed by a strong wind flow from the northwest: thus the pollutant is transported to the opposite side.

Using the case with $h_{s}=3 \mathrm{~m}$ and $M=2.2$ illustrated in Fig. 11b as a reference, increasing either the stack height by a factor of 2.4 (see Fig. 11d) or the momentum ratio by a factor of 2.3 (see Fig. 12b) reveals striking similarities in iso-concentration contour trends. The highest iso-concentration contour value is approximately 720 when stack height is increased (i.e., the reduction in highest $K$ value is about $56 \%$ with respect to the reference case), whereas increasing the pollutant's exhaust velocity 
provides a top iso-concentration contour value about of 668 (i.e., the reduction in highest $K$ value is about $59 \%$ with respect to the reference case). It appears that increasing the height by a factor of 2.4 would be approximately equivalent to doubling the pollutant exhaust velocity on the BE building's windward wall for the reference case $\left(h_{s}=3 \mathrm{~m}\right.$ and $\left.M=2.2\right)$.
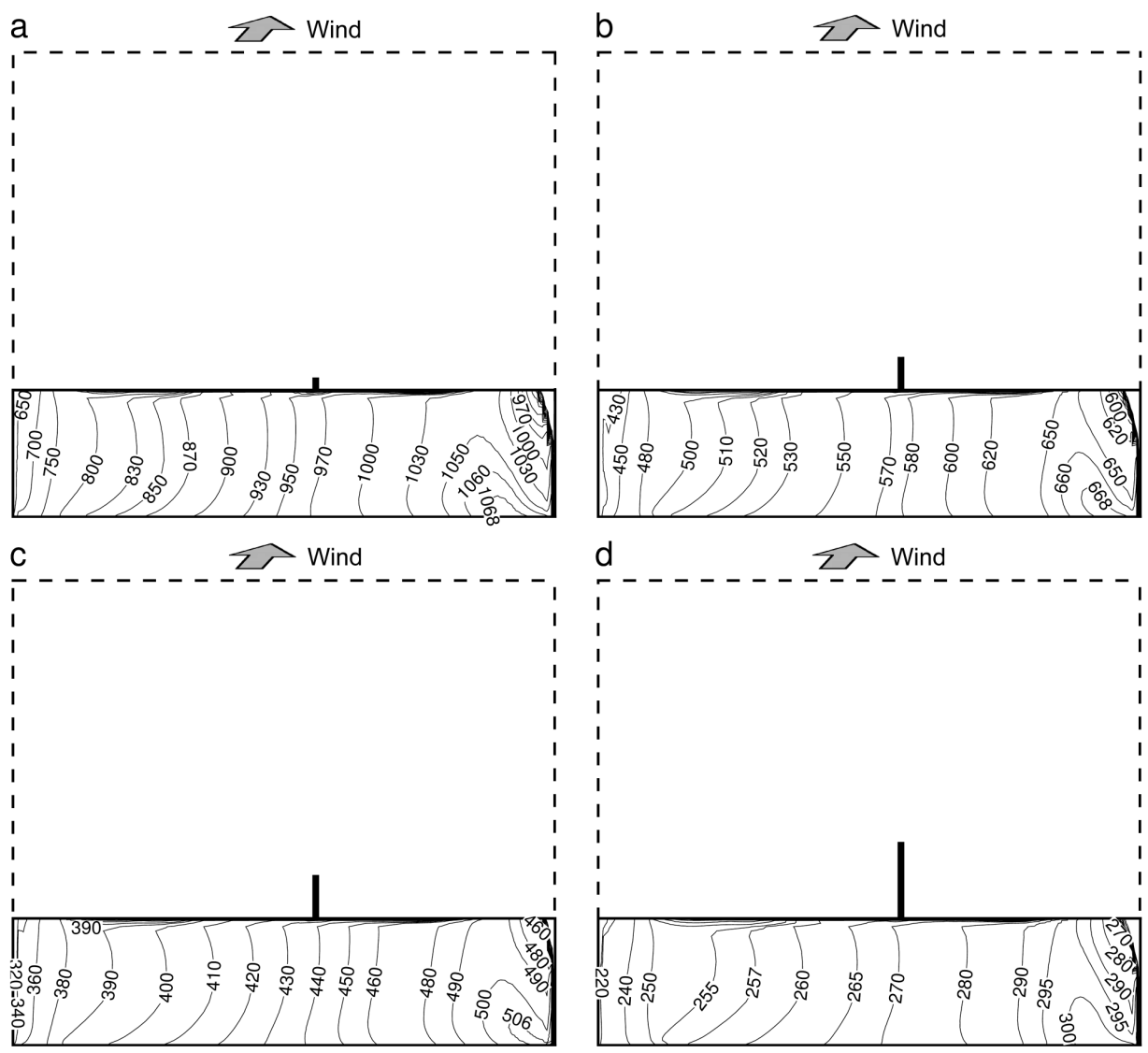

Figure 12: Simulation iso-concentration contours obtained on the windward wall of the BE building for various stack heights $(M=5)$, (a) $h_{s}=1 \mathrm{~m}$, (b) $h_{s}=3 \mathrm{~m}$, (c) $h_{s}=4 \mathrm{~m}$ and (d) $h_{s}=7.2 \mathrm{~m}$.

\subsection{Concentrations on the Faubourg tower's leeward wall for various stack heights}

Figs. 13 and 14 show the non-dimensional iso-concentration contours for various stack heights on the tower's leeward wall, for momentum ratio values of 2.2 and 5, respectively. For the lower stack $\left(h_{s}=1 \mathrm{~m}\right)$ and lower momentum ratio $(M=2.2)$, the iso-contours display arc-like shapes. The highest iso-concentration contour is near the ground, located close to the vertical axis of the stack, as shown in Fig. 13a. The other iso-concentration contours are smeared out around the iso-contour displaying the highest concentration. The contours concentration values decrease gradually as one moves away from the highest iso-concentration contour towards the upper section and sides of the wall. The peaks appearing on the contours may be attributed to the staircase form of the wall. 

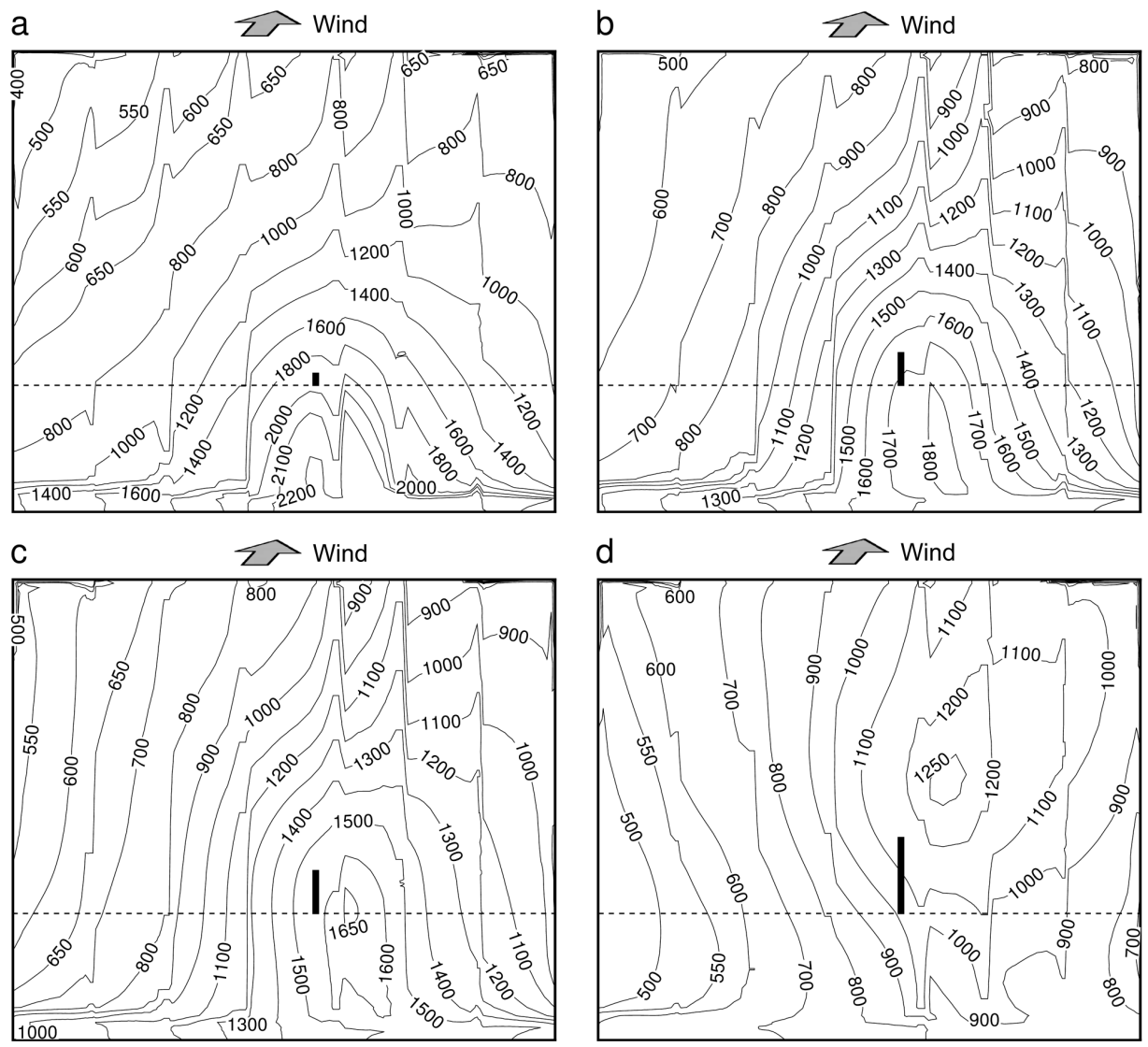

Figure 13: Simulation iso-concentration contours obtained on the leeward wall of the Faubourg tower for various stack heights $(M=2.2)$, (a) $h_{s}=1 \mathrm{~m}$, (b) $h_{s}=3 \mathrm{~m}$, (c) $h_{s}=4 \mathrm{~m}$ and (d) $h_{s}=7.2 \mathrm{~m}$.

The effects of increasing stack height are such that the highest iso-concentration contour decreases in value and moves upwards on the tower's leeward wall. This vertical elevation is very likely due to the staircase form of the wall, which prevents displacement towards the southeast part, despite the wide opening on the northwest side between the two buildings. During its elevation, the highest iso-concentration contour remains at the same horizontal position while horizontal displacement was previously observed on the BE building's windward wall (see Fig. 11). For an increase of the stack height from 1 to 7.2 metres, a decrease in the highest iso-concentration contour value from 2200 to 1250 is noted as shown in Figs. 13a and 13d, respectively (i.e., the reduction in highest $K$ value is about $43 \%$ ).

For a significant momentum ratio $(M=5)$, similar observations are noted as shown in Fig. 14 (i.e., the elevation of the iso-contour displaying the highest concentration along the wall and a decrease in its value as stack height increases). For this momentum ratio $(M=5)$ and for a stack height of 4 metres and higher, the arc-like forms of the iso-concentration contours start to be inversed and become oriented towards the top of the tower's leeward wall, as shown in Figs. 14c and 14d. For the stack height of 1 metre, the highest iso-concentration contour is located at the mid-height on the wall, as indicated in Fig. 14a, whereas as stack height increases to $7.2 \mathrm{~m}$, the uppermost iso-contour reaches the upper region of the wall. 

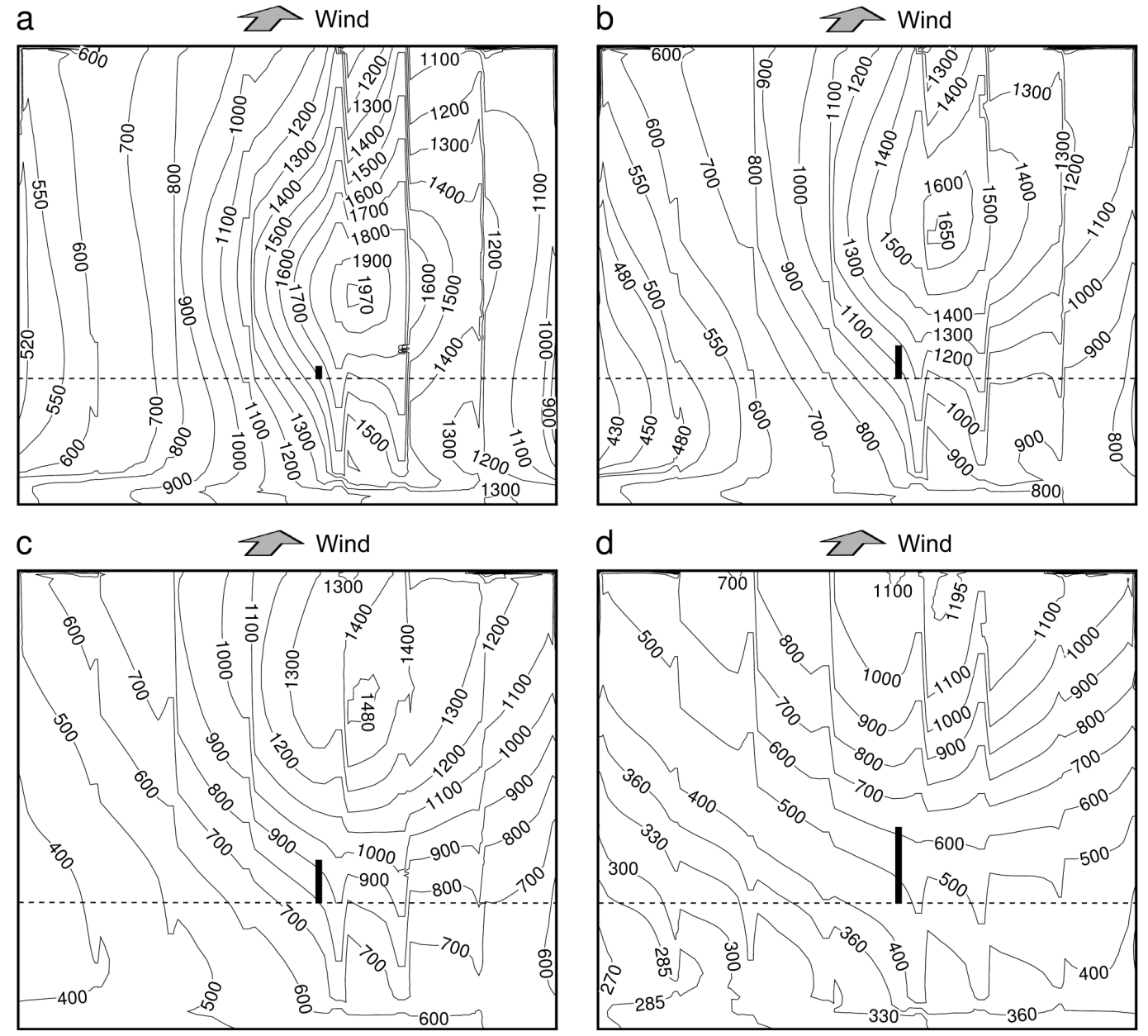

Figure 14: Simulation iso-concentration contours obtained on the leeward wall of the Faubourg tower for various stack heights $(M=5)$, (a) $h_{s}=1 \mathrm{~m}$, (b) $h_{s}=3 \mathrm{~m}$, (c) $h_{s}=4 \mathrm{~m}$ and (d) $h_{s}=7.2 \mathrm{~m}$.

When stack height increases by a factor of 2.4, or when the momentum ratio is doubled with respect to the reference case of $h_{s}=3 \mathrm{~m}$ and $M=2.2$, the behaviour noted previously on the BE building's windward wall is also valid for the Faubourg tower's leeward wall. Contour trend similarities are clearly shown in Figs. 13d and 14b. Increasing stack height by a factor of 2.4 induces a reduction in highest $K$ value of $30 \%$ at the Faubourg tower's leeward wall, while increasing the pollutant exhaust velocity by a factor of 2.3 results in a reduction of only $8 \%$.

\subsection{Concentrations on the BE building's lateral walls for various stack heights}

The evolution of the non-dimensional concentration $K$ along the $x$ direction of both the southeast and northwest lateral side walls of the BE building are shown in Figs. 15a and 15b, respectively, for various stack heights and two momentum ratios $(M=2.2$ and 5$)$. The curves show the distribution of $K$ on the wall at a height of $3 / 4 H_{B E}$ from the ground. This height was selected because here the air intakes are generally located at a rather high elevation from the ground, as recommended by ASHRAE (2007), to remain clear of wind-blown dust, debris and vehicle exhaust. 

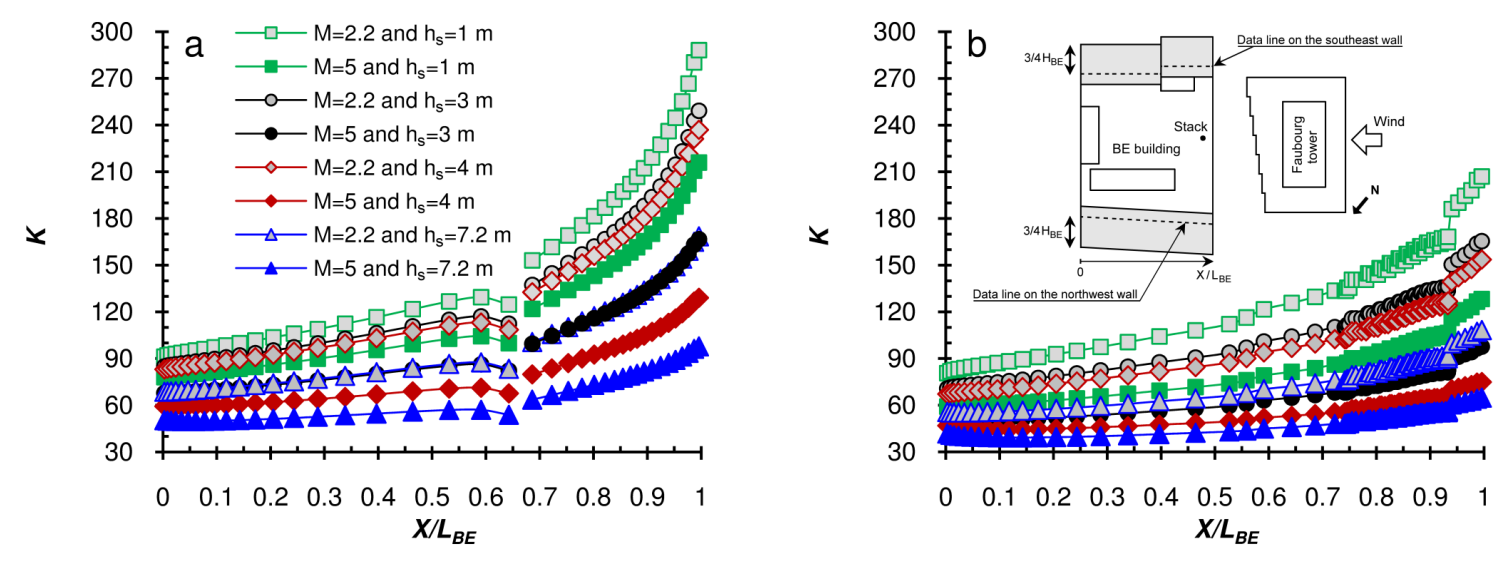

Figure 15: Simulation $K$ profiles at $3 / 4 H_{B E}$ height from the ground for various $h_{s}$ and $M$ on the (a) lateral southeast wall and (b) lateral northwest wall of the BE building.

As shown in Figs. 15a and 15b, the strong concentrations are located in the upstream part of the BE building's two lateral walls for all stack heights and both momentum ratios. The highest pollutant concentrations are recorded along the two sides for the lowest stack $\left(h_{s}=1 \mathrm{~m}\right)$ and for the lower momentum ratio $(M=2.2)$. Small $K$ values are observed for the highest values of both $h_{s}$ and $M$.

The evolution of $K$ on the southeast lateral wall for $h_{s}=7.2 \mathrm{~m}$ and $M=2.2$, shown in Fig. 15a, has similar behaviour to that obtained when increasing the momentum ratio by a factor of $2.3(M=5)$ and reducing stack height by a factor of $2.4\left(h_{s}=3 \mathrm{~m}\right)$. However, considering the northwest lateral wall (Fig. 15b), the stack height should be reduced by a factor slightly above 2.4 in order to obtain the same evolution when increasing the pollutant exhaust velocity by a factor of 2.3 . In other words, the connecting factor between stack height and pollutant exhaust velocity must be selected with care and should take into account the surface of interest if one wishes to obtain absolute similarity between these two parameters. Lastly, if the circumstances impose air intakes on the BE building's lateral sides, these should be located to the rear of each lateral side.

\subsection{Concentrations around the hypothetically isolated BE building without the upstream Faubourg tower}

This section sets out the case while intentionally excluding the Faubourg tower upstream of the $\mathrm{BE}$ building. The parameters considered are $h_{s}=1 \mathrm{~m}$ and $M=2.2$. Figs. 16a and 16b show the computed non-dimensional iso-concentration contours on the roof and the windward wall of the BE building, respectively. The iso-concentration contours obtained without taking the upstream tower into account are completely different from those presented previously when including the presence of the tower.

Iso-concentration contour values are negligible on the BE building's windward wall and much greater on the central part of the roof. Given the well-known $(i)$ features of the wind pattern around an isolated building with a perpendicular wind to its windward facade, as described by ASHRAE (2009), and (ii) the dispersion evolution of roof stack pollutant emitted from the upwind part of a roof, as summarized by Blocken and Stathopoulos (2008), the vortices of the recirculation zone occurring at the upstream edge of the roof serve to trap the pollutant and increase the concentration values in this region, as indicated in Fig. 16a. However, far downstream, although the concentration values decrease in the central region, they remain significant. 

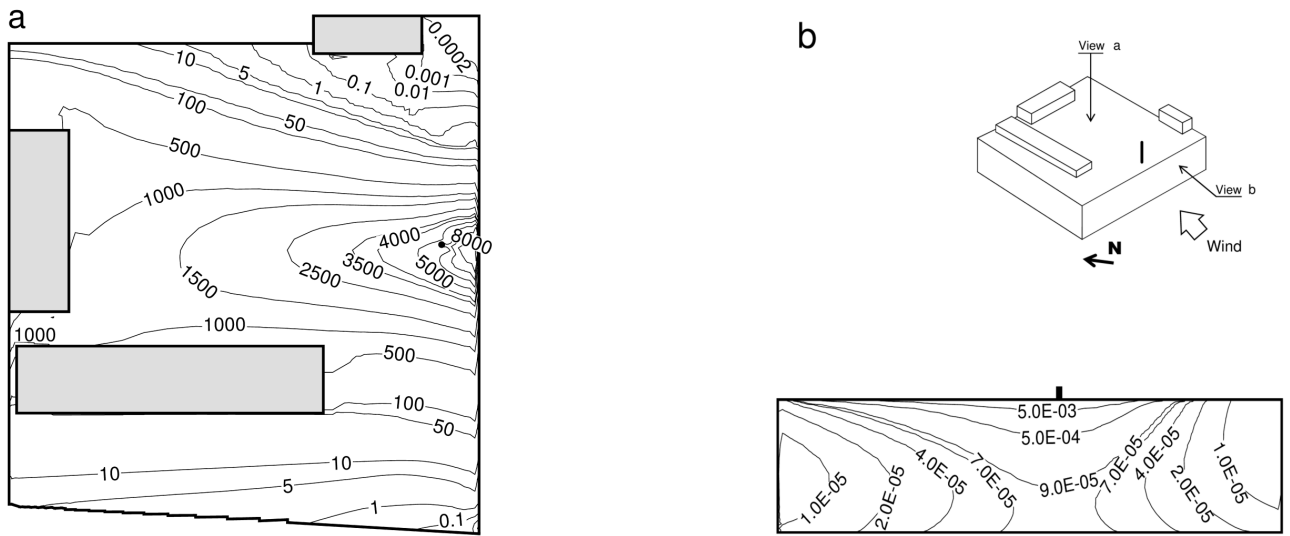

Figure 16: Simulation iso-concentration contours obtained without taking the Faubourg tower upstream into account, for $h_{s}=1 \mathrm{~m}$ and $M=2.2$, (a) on the BE building's roof and (b) on the BE building's windward wall.

At the lateral parts of the roof, concentrations are diluted by the wind flow circumventing the building, and this greatly lowers iso-concentration contour values. Locations that remain better adapted for fresh-air intakes are: the building's windward wall, where concentrations are otherwise close to zero; or the lateral side walls, where the values are very low. Since most of the pollutant is led to the wake region, it is obvious that the building's leeward wall must be avoided as a location for fresh-air intakes.

\section{Conclusions}

This paper has investigated the dispersion of a pollutant emitted from a roof stack in the wake of a tower, in a two-building configuration. It was carried out at wind tunnel scale (1:200) by numerical simulation (CFD) with the realizable $k-\epsilon$ turbulence model. This study examines the effect of stack height and pollutant exhaust velocity on the distribution of pollutant concentration on the emitting building's walls as well as on the leeward wall of the tower, to determine the best locations for fresh-air intakes for the building. As a result of this study, conclusions for the configuration examined can be summarized as follows:

- Neglecting the impact of the Faubourg tower in the upstream of the building of interest leads to considerable errors in pollutant dispersion patterns. Clearly, omitting the upwind tower can lead to major design errors regarding the location of fresh-air intakes. For example, the presence of the tower induces a decrease in concentration values of about $95 \%$ on the emitting building's roof centre.

- Increasing the stack height has an effect that is similar to increasing the pollutant exhaust velocity and the nature of this effect depends upon the wall of the building under consideration. An example for the cases presented: a stack height of 3 metres with a momentum ratio of 2.2 will display approximately the same iso-concentration contour configuration on the emitting building's roof when stack height and momentum ratio are increased by factors higher than 2 .

- On the emitting building's windward wall and the upstream tower's leeward wall, distribution of the iso-concentration contours remains the same for the example quoted above $\left(h_{s}=3 \mathrm{~m}\right.$ and $M=2.2$ ) when increasing the two parameters $h_{s}$ and $M$ by factors higher than 2 . However, the reduction in highest iso-concentration contour value obtained on the tower's leeward wall is $22 \%$ less when increasing momentum ratio than when increasing stack height. On the emitting building's windward wall, the opposite tendency is observed: increasing momentum ratio provides $3.2 \%$ higher value for the highest iso-concentration contour than does increasing stack height. Given this difference, it would be worthwhile to study which parameter should be modified in order to reduce pollution in certain places. However, the uncertainty of the concentration in the wind tunnel tests is about $5 \%$, as mentioned by Stathopoulos et al. (2004). 
- Varying these two parameters does not sufficiently alter the concentration displayed on the emitting building's leeward wall. Their values remain the lower concentrations recorded on these building's walls; this does appear to be the best location for the fresh-air intakes, however. On the other hand, for the upstream tower, fresh-air-intake locations should not be placed on the leeward wall because of the high pollutant concentrations recorded there.

\section{Acknowledgements}

Financial support for this study from the Fonds Québécois de la Recherche sur la Nature et les Technologies $(F Q R N T)$ is gratefully acknowledged. The authors would also like to express their special appreciation to the Institut de Recherche Robert-Sauvé en Santé et Sécurité de Travail (IRSST) team of Montreal, Canada for their cooperation.

\section{References}

ASHRAE, 1997. Chapter 15: Airflow around buildings. In: ASHRAE handbook - Fundamentals. American Society of Heating, Refrigerating and Air-conditioning Engineers, Atlanta, USA.

ASHRAE, 2007. Chapter 44: Building air intake and exhaust design. In: ASHRAE handbook Heating, Ventilating, and Air-Conditioning Applications. American Society of Heating, Refrigerating and Air-conditioning Engineers, Atlanta, USA.

ASHRAE, 2009. Chapter 24: Airflow around buildings. In: ASHRAE handbook - Fundamentals. American Society of Heating, Refrigerating and Air-conditioning Engineers, Atlanta, USA.

Blocken, B., Stathopoulos, T., 2008. On the use of CFD for modelling air pollutant dispersion around buildings. In: The 4th International Conference on Advances in Wind and Structures (AWAS'08), Jeju, Korea, 37-55.

Blocken, B., Stathopoulos, T., Carmeliet, J., 2007. Cfd simulation of the atmospheric boundary layer: wall function problems. Atmospheric Environment 41 (2), 238-252.

Blocken, B., Stathopoulos, T., Carmeliet, J., Hensen, J. L. M., 2011. Application of computational fluid dynamics in building performance simulation for the outdoor environment: an overview. Journal of Building Performance Simulation. In press. doi: 10.1080/19401493.2010.513740.

Blocken, B., Stathopoulos, T., Saathoff, P., Wang, X., 2008. Numerical evaluation of pollutant dispersion in the built environment: comparisons between models and experiments. Journal of Wind Engineering and Industrial Aerodynamics 96 (10-11), 1817-1831.

Celik, I. B., Ghia, U., Roache, P. J., Freitas, C. J., Coleman, H., Raad, P. E., 2008. Procedure for estimation and reporting of uncertainty due to discretization in CFD applications. Journal of Fluids Engineering 130 (078001), 1-4.

Chavez, M., Hajra, B., Stathopoulos, T., Bahloul, A., 2011. Near-field pollution dispersion in the built environment by CFD and wind tunnel simulations. Journal of Wind Engineering and Industrial Aerodynamics 99 (4), 330-339.

Contini, D., Cesari, D., Donateo, A., Robins, A. G., 2009. Effects of Reynolds number on stack plume trajectories simulated with small scale models in a wind tunnel. Journal of Wind Engineering and Industrial Aerodynamics 97 (9-10), 468-474.

Franke, J., Hellsten, A., Schlunzen, H., Carissimo, B., 2007. Best practice guideline for the CFD simulation of flows in the urban environment. vol. 732. COST Action. 
Gousseau, P., Blocken, B., Stathopoulos, T., van Heijst, G. J. F., 2011. CFD simulation of near-field pollutant dispersion on a high-resolution grid: a case study by LES and RANS for a building group in downtown Montreal. Atmospheric Environment 45 (2), 428-438.

Lateb, M., Masson, C., Stathopoulos, T., Bédard, C., 2010a. Numerical simulation of pollutant dispersion around a building complex. Building and Environment 45 (8), 1788-1798.

Lateb, M., Masson, C., Stathopoulos, T., Bédard, C., 2010b. Influence of turbulence models on pullutant dispersion studies around a building complex. In: The Fifth International Symposium on Computational Wind Engineering (CWE2010), Chapel Hill, NC, USA, 1-8.

Meinders, E. R., Hanjalic, K., 1999. Vortex structure and heat transfer in turbulent flow over a wallmounted matrix of cubes. International Journal of Heat and Fluid Flow 20 (3), 255-267.

Meroney, R. N., Leitl, B. M., Rafailidis, S., Schatzmann, M., 1999. Wind-tunnel and numerical modeling of flow and dispersion about several building shapes. Journal of Wind Engineering and Industrial Aerodynamics 81 (1-3), 333-345.

Murakami, S., Mochida, A., Hayashi, Y., Hibi, K., 1991. Numerical simulation of velocity field and diffusion field in an urban area. Energy and Buildings 15 (3-4), 345-356.

Nakiboglu, G., Gorlé, C., Horváth, I., Beeck, J. V., Blocken, B., 2009. Stack gas dispersion measurements with large scale-PIV, aspiration probes and light scattering techniques and comparison with CFD. Atmospheric Environment 43 (21), 3396-3406.

Onbasioglu, S. U., 2001. On the simulation of the plume from stacks of buildings. Building and Environment 36 (4), 543-559.

Ratcliff, M. A., Sandru, E., 1999. Dilution calculations for determining laboratory exhaust stack height. American Society of Heating, Refrigerating and Air-conditioning Engineering, 1-5.

Santos, J. M., Reis, N. C., Goulart, E. V., Mavroidis, I., 2009. Numerical simulation of flow and dispersion around an isolated cubical building: the effect of the atmospheric stratification. Atmospheric Environment 43 (34), 5484-5492.

Sini, J. F., Anquetin, S., Mestayer, P. G., 1996. Pollutant dispersion and thermal effects in urban street canyons. Atmospheric Environment 30 (15), 2659-2677.

Stathopoulos, T., 2006. Pedestrian level winds and outdoor human comfort. Journal of Wind Engineering and Industrial Aerodynamics 94 (11), 769-780.

Stathopoulos, T., Lazure, L., Saathoff, P., Gupta, A., 2004. The effect of stack height, stack location and rooftop structures on air intake contamination: A laboratory and full-scale study. In: Report R-392. Institut de recherche Robert-Sauvé en santé et en sécurité du travail (IRSST), IRSST/Report392.

Tominaga, Y., Stathopoulos, T., 2009. Numerical simulation of dispersion around an isolated cubic building: comparison of various types of $k-\epsilon$ models. Atmospheric Environment 43 (20), 3200-3210.

Tominaga, Y., Stathopoulos, T., 2010. Numerical simulation of dispersion around an isolated cubic building: model evaluation of RANS and LES. Building and Environment 45 (10), 2231-2239.

Wang, X., 2006. Numerical simulation of wind - induced dispersion of emissions from rooftop stacks. M.A.Sc Thesis, Department of Building, Civil and Environmental Engineering, Concordia University, Montreal, Canada.

White, B. R., Stein, W., 1990. Wind-tunnel studies of variable stack heights for a low-profile building. Journal of Wind Engineering and Industrial Aerodynamics 36 (1-3), 675-687. 
Yassin, F. M., Kato, S., Ooka, R., Takahashi, T., Kouno, R., 2005. Field and wind-tunnel study of pollutant dispersion in a built-up area under various meteorological conditions. Journal of Wind Engineering and Industrial Aerodynamics 93 (5), 361-382. 